\title{
Tetanus Toxoid Induced Anaphylaxis
}

\section{Saibal Das ${ }^{1 *}$ and Somnath Mondal ${ }^{2}$}

${ }^{1}$ House physician, General emergency, NRS Medical College and Hospital, Kolkata 700014 , India

${ }^{2}$ Department of Clinical and Experimental Pharmacology, Calcutta School of Tropical Medicine, Kolkata 700073 , India

\begin{abstract}
This case report highlights an anaphylaxis reaction induced by intramuscular tetanus toxoid (TT) injection in a 6 year old girl having the first time exposure to this drug. TT is a commonly used vaccine used for active immunization against Clostridium tetani and is included in the National Immunization Schedule of India. Although TT is a very safe vaccine, its adverse reactions include local edema, tenderness, fever and may rarely induce life-threatening anaphylactic response, the potential causative agents can be TT antigens, aluminum phosphate or thimerosal preservative. Before its intramuscular administration, cutaneous hypersensitivity testing should be done routinely and there should be provisions for emergency measures in cases of anaphylaxis.
\end{abstract}

Keywords: Tetanus toxoid; Hypersensitivity; Anaphylaxis

Abbreviations: TT: Tetanus Toxoid; DPT: Diphtheria, Pertussis, Tetanus; DT: Diphtheria, Tetanus; IgE: Immunoglobulin E

\section{Introduction}

Tetanus toxoid (TT) is a commonly used vaccine used for active immunization against Clostridium tetani [1]. It is also included in the National Immunization Schedule of India [2] and many other countries. It is given intramuscularly either alone or along with diphtheria toxoid and pertussis vaccine [3]. Purified TT (adsorbed) has largely replaced plain toxoid because it stimulates higher and longer immune response [4]. Hypersensitivity reactions following TT injections are uncommon and less likely to occur with purified TT adsorbed in aluminium phosphate, stored between 4 and $10^{\circ} \mathrm{C}[4]$.

\section{Case History}

A 6 year old girl presented with a minor cut injury in her left hand. After examination, she was prescribed injection TT intramuscularly. She was injected $0.5 \mathrm{ml}$ TT intramuscularly in left arm without prior intra dermal sensitivity test. 5 minutes after the injection, the girl felt progressive respiratory distress, tightness in chest, dizziness, gradual swelling of lips and eyelids, flushing associated with intense itching of the whole body.

On examination, her pulse rate was found to be 150 per minute, blood pressure $80 / 56 \mathrm{~mm}$ of $\mathrm{Hg}$ with evidence of wheeze and wellcircumscribed urticarial eruptions of the whole body. She was diagnosed to have an anaphylactic shock. Immediately she was treated with moist oxygen inhalation, $0.5 \mathrm{ml}$ subcutaneous injection of adrenaline, intravenous infusion with normal saline with $10 \mathrm{mg} / \mathrm{kg}$ intravenous hydrocortisone and $50 \mathrm{mg}$ intramuscular diphenhydramine. All of her symptoms were gradually improved and condition was stabled.

Thorough history taking revealed she never took any tetanus toxoid vaccines (either singly or in combination with other vaccines likes diphtheria or pertussis) as per the National Immunization Schedule of India, so this was the first time she was exposed to intramuscular TT injection. There was no resent or past history of any respiratory diseases in the patient. She neither took any new food for the first time on that day nor was exposed to any new chemicals. There was no history of any concomitant medications for the last 2 weeks. There were no evidences of other acute respiratory decompensation from severe asthma attacks, foreign body aspiration, pulmonary embolism, hereditary angioedema, seizure disorders, myocardial infarction and arrhythmia.
She was diagnosed to suffer from TT induced anaphylaxis, as there was a temporal relationship between the administration of the drug and the adverse event. Re-challenge was however not done.

\section{Discussion}

Naranjo adverse drug reaction probability scale suggested that there was a "probable" relationship between administration of TT and occurrence of anaphylaxis [5].

The TT adsorbed USP used was a sterile suspension of alumprecipitated (aluminum potassium sulfate) toxoid in an isotonic sodium chloride solution containing sodium phosphate buffer. $0.5 \mathrm{~mL}$ contained $5 \mathrm{Lf}$ (flocculation units) of tetanus toxoid and $0.22 \mathrm{mg}$ of aluminum.

TT is otherwise a very safe vaccine. Adverse reactions to TT vaccine are mostly mild and limited to the injection site [6]. The most common adverse reactions include local edema and tenderness, fever and anaphylactoid response [7]. It may also cause delayed hypersensitivity responses with leukocyte migration inhibition [8]. Immunoglobulin $\mathrm{E}$ (IgE) mediated reactions may occur, and the incidence of anaphylactic responses to TT immunization is as less as $0.001 \%$. When TT induces an allergic reaction, the potential causative agents can be TT antigens, aluminum phosphate or thimerosal preservative [6].

Since TT is very widely used, before administration, the physician should bear in mind the possibility of occurrence of hypersensitivity reaction and make provisions for taking emergency measures. Past history of allergy to TT, DPT (Diphtheria, Pertussis, Tetanus) or DT (Diphtheria, Tetanus) should be taken. Routine cutaneous hypersensitivity testing for TT before intramuscular administration can be employed as a relatively safe and simple procedure [9].

*Corresponding author: Dr. Saibal Das, MBBS, House physician, Genera emergency, NRS Medical College and Hospital, Residential address: 14 Kabi Sukanta Lane, P.O. Santoshpur, Kolkata, India, Tel: +91339433429401, +913324139781; E-mail: saibaldas123@gmail.com

Received February 02, 2012; Accepted February 27, 2012; Published February 29, 2012

Citation: Das S, Mondal S (2012) Tetanus Toxoid Induced Anaphylaxis. J Vaccines Vaccin 3:126. doi:10.4172/2157-7560.1000126

Copyright: @ 2012 Das S, et al. This is an open-access article distributed under the terms of the Creative Commons Attribution License, which permits unrestricted use, distribution, and reproduction in any medium, provided the original author and source are credited. 


\section{References}

1. Abrutyn E (2008) Tetanus. Harrison's Principles of Internal Medicine, Vol 1: $17^{\text {th }}$ ed. New York: McGraw-Hill, 133: 898-900.

2. World Health Organization. Country office for India. [Homepage on the internet]. National Immunization Schedule.

3. Ananthanarayan R, Paniker CKJ (2005) Clostridium. Ananthanarayan and Paniker's Textbook of Microbiology. $7^{\text {th }}$ ed. India: Orient Longman; 28: 248-65.

4. Park K (2002) Epidemiology of communicable diseases: Tetanus. Park's textbook of Preventive and Social Medicine. $19^{\text {th }}$ ed. Jabalpur, India: Banarsidas Bhanot; 5: 260-264.
5. Naranjo algorithm.

6. Mayorga C, Torres MJ, Corzo JL, Alvarez J, García JA, et al. (2003) Immediate allergy to tetanus toxoid vaccine: determination of immunoglobulin $E$ and immunoglobulin $G$ antibodies to allergenic proteins. Ann Allergy Asthma Immunol 90: 238-243.

7. Jacobs RL, Lowe RS, Lanier BQ (1982) Adverse reactions to tetanus toxoid JAMA 247: 40-42.

8. Johnson C, Walls RS, Ruwoldt A (1983) Delayed hypersensitivity to tetanus toxoid in man: in vivo and in vitro studies. Pathology 15: 369-372.

9. Mansfield LE, Ting S, Rawls DO, Frederick R (1986) Systemic reactions during cutaneous testing for tetanus toxoid hypersensitivity. Ann Allergy 57: 135-137. 